\title{
Minimum Heart Rate
}

National Cancer Institute

\section{Source}

National Cancer Institute. Minimum Heart Rate. NCI Thesaurus. Code C62096.

The maximum time between successive cycles of contraction and subsequent relaxation

of the heart, usually expressed as beats per minute, obtained from a set of

measurements of the heart rate. 